\title{
L'Imaginaire antillais
}

C omment caractériser l'imaginaire antillais? ... de ce nouveaux-vieux monde, foyer de cultures multiples et fécondes? L'imaginaire antillais est fait de temps, d'espace et d'esprit. C'est une imagination colorée d'abord par la géographie particulière de ces terres situées entre Nord et Sud, de ce monde in-between, centre insulaire et fragmenté; et puis, aussi par sa démographie qui miroite toutes les races humaines, dont les racines s'entrelacent et se répandent au-delà des continents et des océans. Et pourtant, sociétés non-ataviques, dit Raphaël Confiant. Mais sûrement, peuples qui ont épousé la souffrance, qui se sont faits à l'errance et à l'exil.

Lieux bénis de sables, de mers chaudes et limpides, de calme sargassien, de végétation luxuriante; mais aussi lieux maudits, soumis aux intempéries naturelles, aux ravages des ouragans, des inondations, des éruptions volcaniques.

Mémorable, la destruction de Saint-Pierre et ses 30.000 habitants en $1902-$ naufrage ardent d'une ville plus que titanique!

Effrayante, la menace actuelle de la Soufrière!

Ces cataclysmes et ces dévastations ont fortifié la volonté et l'esprit de ces peuples, habitués aux recommencements, à la re-naissance continuelle. Ces peuples, comme leurs volcans, vivent toujours la fermentation. Soumis aux represseurs, soulevés par des révolutionnaires, ils se nourrissent quotidiennement d'intemporel et de réalisme, d'aspirations et de labeurs, de misères et de grandeurs.

L'Histoire aussi a forgé leur imaginaire. Leur mémoire est hantée par le spectre des cargaisons de l'esclavage, par les révoltés damnés de Saint-Domingue, par l'usure 
inhumaine des plantations. Mais leur coeur demeure gonflé d'esprit de résistance, d'espérance, de survivance.

Ces antinomies habitent leur esprit créateur, alimenté d'histoire et de géographie, de révolte et de paix, d'exil et de nostalgie. Esprit créateur toujours enchaîné et défiant, martyrisé et racheté, saccagé et glorieux. Ces terres sont un chaudron générateur d'énergie inépuisable. Ces lieux attisent une dialectique toujours créatrice. Négritude, indigénisme, francophonie, créolité, etc. se côtoient, s'entrecroisent et se tiraillent pour enfin donner expression à des créations vigoureuses et protéiformes.

Une littérature - en français, en créole - dont les débuts remontent au dix-septième siècle, n'est pas certainement naissante; mais, comme ses sociétés, elle est toujours en voie de se définir, de s'orienter, se s'auto-déterminer. Cette littérature, dont les aspects majeurs sont finement étudiées et illustrées dans les pages qui suivent, vit encore l' âge de formation, telle une jeune adolescente émancipée et souriante, mais qui boude encore de temps en temps; pleine de vigueur et d'ambition, elle accepte mal les contraintes; dépendante et rebelle à la fois, elle affiche d'or et déjà, parmi des moments d'hésitation et d'abattement, des signes certains de grandeur et de beauté.

\section{Sergio Villani}

Université York

\section{Remerciements:}

Je tiens à remercier tous les collègues qui ont contribué des articles à ce numéro spécial. Je remercie également de leur générosité les poètes, les romanciers et les artistes qui nous ont offert les fruits de leur créativité. Enfin, $j$ 'apprécie énormément l'aide de tous ceux qui m'ont donné leurs conseils, leur temps, des renseignements et beaucoup d'encouragement dans la réalisation de ce projet; en particulier, Rodney Saint-Eloi, Jacqueline Beaugé-Rosier, MarieCélie Agnant, Thomas Spears et Joëlle Vitiello.

S.V. 